\title{
LARGE BOWEL OBSTRUCTION ASSOCIATED WITH RENAL HYPERNEPHROMA \\ A Case Report
}

\author{
Squadron-Leader J. PATRICK, F.R.C.S., R.A.F. (Retd.) \\ Squadron-Leader P. T. KING, M.B., B.Sc., D.M.R.D., F.R.C.R., R.A.F. \\ Royal Air Force Hospital, Cosford.
}

\section{Introduction}

Extramural large bowel obstruction and metastasis in the liver from a hypernephroma is rare. This case is presented to demonstrate the difficulties of diagnosis, the hormone dependency of the secondary tumour after nephrectomy, and the relief of symptoms by hepatic artery ligation.

\section{Case Report}

A 40-year old Flight Sergeant in the Royal Air Force, previously fit apart from an appendicectomy 19 years before, was admitted on 15 September 1971 with a five-day history of lower abdominal pain, absolute constipation and no passage of flatus for 3 days, plus retching and vomiting for 24 hours. He was anorexic and had lost half a stone in weight in the previous two weeks. He was colour blind for red/green, so although he had noted 'dark' urine in preceeding days he did not complain of haematuria. His bowel function had previously been regular.

On examination he was jaundiced and ill, with a generally tender abdomen containing a large tender mass in the left upper quadrant which moved with respiration. This mass was dull in the flank but resonant more medially and spread as far as the midline. It was not notched. There was no shifting dullness, and no other abnormal findings.

The abdomen was not distended, occasional bowel sounds were heard. Rectal examination was normal and no faeces were felt. His left testis and cord were tender. A diagnosis of large bowel obstruction was made, an intravenous infusion and nasogastric suction was instituted and an enema administered (with very little result). Straight abdominal X-ray showed fluid levels and a soft tissue mass in the upper left quadrant (Fig. 1). After initial resuscitation an infusion pyelogram (I.V.P.) was performed (Fig. 2) which showed a large mass at the lower pole of the left kidney with displacement of the left ureter. A barium enema showed an extrinsic mass compressing the descending colon (Fig. 3). A Foley catheter was passed for he had difficulty in initiating micturitation. The urine contained blood. The following laboratory results were obtained:

Haemoglobin $12.6 \mathrm{~g} / 100 \mathrm{ml}$. White blood-cell count was normal. Electrolytes were also normal. Total bilirubin $3.3 \mathrm{mg} / 100 \mathrm{ml}$ (unconjugated $1.3 \mathrm{mg} / 100 \mathrm{ml}$ ). Urea 47 $\mathrm{mg} / 100 \mathrm{ml}$. Alkaline phosphatase 18.4 King-Armstrong units/100 ml. Serum glutamic oxaloacetic-acid-transaminase was normal. Total protein $7.4 \mathrm{mg} / 100 \mathrm{ml}$. Chest X-ray showed no evidence of secondaries.

Laporatomy was planned but after several enemata in preparation his condition improved-he passed flatus and was no longer obstructed. Arrangements were made for 


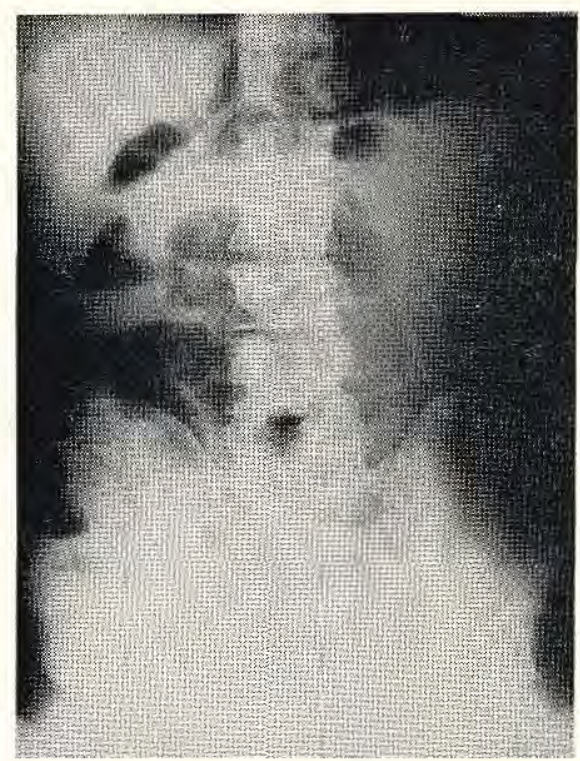

Fig. 1. Straight abdominal $\mathrm{X}$-ray showing fluid levels and a soft tissue mass in the upper left quadrant.

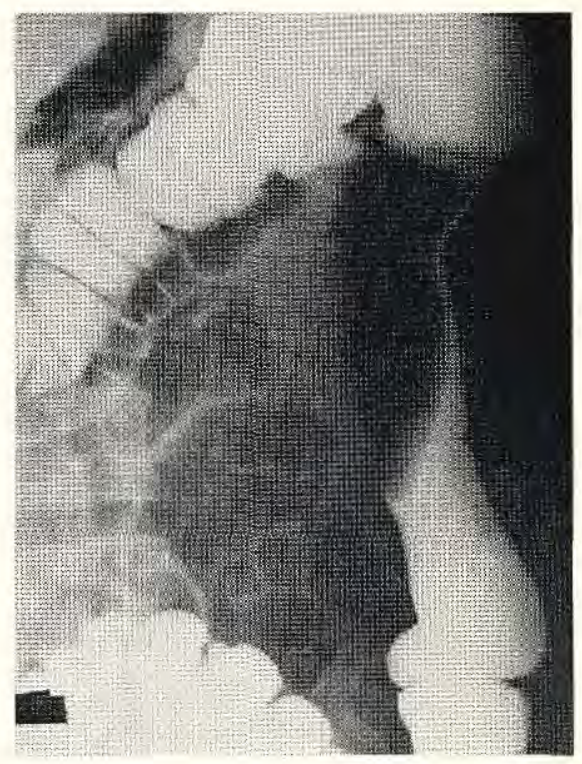

Fig. 3. A barium enema showing an extrinsic mass compressing the descending colon.

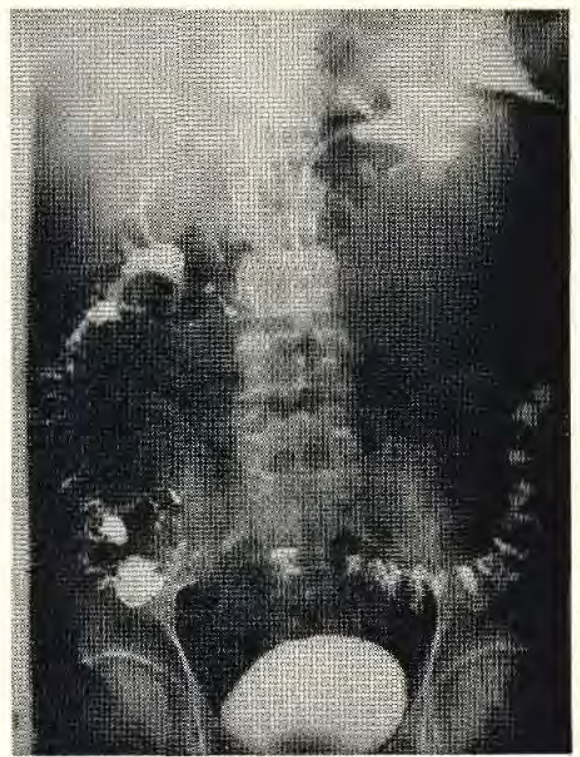

Fig. 2. Infusion pyelogram showing a large mass at the lower pole of the left kidney with displacement of the left ureter.

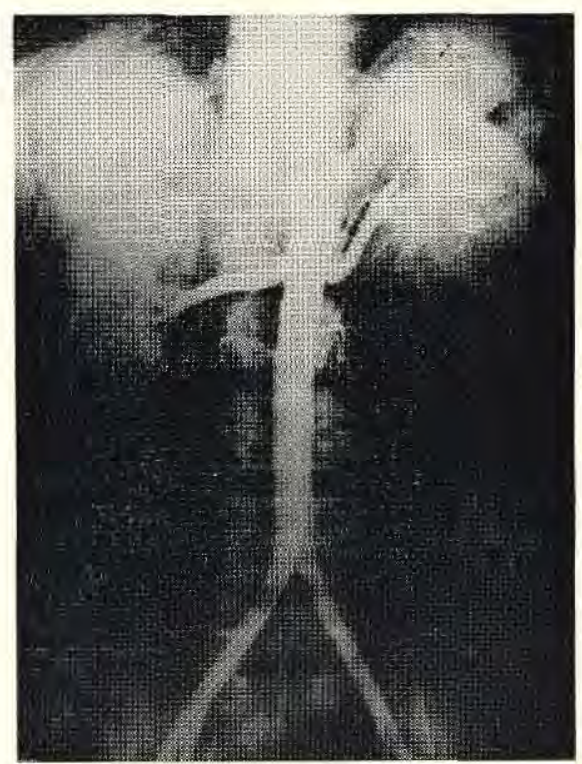

Fig. 4. Post-angiogram film giving the impression of a renal cyst, still bleeding, or at least showing internal rupture into the calyceal system.

a selective renal arteriogram to be performed. The next day he developed a left varicocoele. 
Five days later the selective renal arteriogram showed that the left renal artery was displaced upwards with the kidney. The renal branches were normal apart from the displacement. A good upper and mid-pole nephrogram was obtained but the lower pole outlined was irregular. The filling defect dependent from the lower pole was avascular but showed:

(a) Faint increase in density generally. (b) Faint rim opacification.

Further films taken post-angiogram showed contrast passing from the calyceal system into the opacity. "The impression was of a renal cyst, still bleeding, or at least showing internal rupture into the calyceal system " (Fig. 4). However, the clinical findings were so suggestive of renal carcinoma that the patient was subjected to transperitoneal exploration of the left kidney.

\section{Operative findings}

A tumour the size of a melon was found in the lower pole of the left kidney. There was no invasion of the renal vein, though the left testicular vein was grossly enlarged - thought to be a pressure effect. There were no para-aortic nodes, neither was there any extra-capsular local invasion" but a large secondary deposit was discovered in the Lobe of the liver. This was aspirated, but only blood was obtained. On cutting into this tumour golden yellow, friable, tissue was found and biopsied.

A left nephrectomy was performed. The tumour was subsequently proven to be a cystic degenerative adenocarcinoma on histological examination. Consideration was given at this stage to performing a left partial hepatectomy as the secondary appeared to be the only one present (Skeletal survey was negative, as was a repeat chest X-ray). Bone scan was not performed.

Accordingly a portal venogram was performed under general anaesthetic by catheterisation of the umbilical vein. The films while diagnostic were not of a sufficiently high standard to permit reproduction. They showed several secondaries in the right lobe of the liver as well as the previously discovered left lobar deposit. Therefore, surgery was not performed. Cyclophosphamide + progesterone (Provera) chemotherapy was begun, in the hope that this carcinoma was hormone-dependent.

The palpable hepatic mass disappeared and the patient's weight increased by two stones over the next five months. He felt very much better and returned to light work. The dose of progesterone was increased to $100 \mathrm{mg}$ per day (Bloom 1971). One month later, however, the patient developed severe hypochondrial pain, and at re-laparotomy the left lobe metastic deposits were found to involve the anterior abdominal wall and peritoneum. The hepatic artery was tied and portal perfusion with 5-thiouracil begun. He recovered slowly from this procedure, his progress being complicated by pneumonia and a deep vein thrombosis of the left calf.

Following his hepatic ligation and stormy recovery he was discharged home with some initial reduction in pain and in the size of the liver deposits. At this stage he was treated with high dose progesterone and analgesia (Fortral).

He was relatively well for about three months and then began to gradually deteriorate with increasing pain. The liver was now markedly enlarged. No bone metastases were found. He was stabilised on Fortral and chlorpromazine and continued with high dose progesterone. 
He was re-admitted for terminal care some eight months later and died some 2 years after his initial presentation.

\section{Discussion}

Renal adenocarcinoma can present in many ways. Extrinsic large bowel obstruction as one of them is not common, and this case is reported for this reason. A cyst puncture was not done at the arteriogram and may possibly have helped in the correct diagnosis.

The operative findings, however, suggested a single liver metastasis and thought was given to treating this apparently solitary growth by hepatic resection in the same way as has been reported (Effler and Blades 1948, Ewert 1954, Barney and Churchill 1939) for lung metastasis from hypernephroma following successful nephrectomy. Wilkins, Burke and Head (1961) have stated that solitary lung secondary growths from the kidney, some bone tumours, colon and uterus do well when treated aggressively by surgical resection after appropriate operative treatment to the primary growth. They claimed a 26 per cent five-year further survival for such cases. A search of the literature has not revealed a successful case treated in this manner when the tumour has spread to the liver. Heger (1970) reported a case of hepatic metastasis which he suggested was due to mesenteric vein penetration and subsequent embolisation to the liver. Although possible in our case, tumour involvement of the portal system was not obvious at laparotomy. Liver spread is rare-hypernephroma usually spreads both locally and to draining para-aortic lymph glands and also spreads along the renal vein and thus to the lung via the inferior vena cava and thence systematically. Rare secondary deposits have been found in the thyroid, brain, metacarpals, radius and vagina, liver and pancreas. In this case a portal venogram showed inoperable tumour deposits throughout the liver so further procedures were avoided. The patient did very well initially with large doses of progesterone + cyclophosphamide but the response was limited (Bloom 1971) and eventually hepatic artery ligation was necessary for the control of symptoms (Markowitz 1952, Madding, Kennedy and Sogemeier 1970).

\section{Acknowledgements}

Or thanks are due to the Director-General of Medical Services, Royal Air Force for permission to publish, and to Air Commodore J. Malcolm, Group Captain P. Sutton, Consultant Advisers in Surgery and Radiology respectively for their unfailing help and encouragement.

\section{REFERENCES}

BARNeY, D. and ChURCHILl, E. J. (1939). Adenocarcinoma of the kidney with metastases to the lung. J. Urol. (Baltimore) 42, 269-276.

Bцоом. H. J. (1971). Provera in the treatment of metastatic renal cancer. Brit. J. Cancer 25, 250-265.

EFFLER, D. B. and BLADES, B. (1948). Surgical treatment of solitary lung metastases. J. thorac. Surg. 17, 27-37.

EWERT, E. E. (1954). Apparently unilateral solitary pulmonary metastasis from renal cell carcinoma. Surg. clin. N. Amer. 34, 807-808.

Heger, N. (1970). Hypernephroid carcinoma with trra- and pre-renal arteriovenous fistula, mesenteric vein penetration and massive hepatic metastasis. Fortschr. Rontgenstr. 112, 537-540.

Madding, G. F., KenNedy, P. A. and Sogemeier, E. Hepatic artery ligation for metastic neoplasm in the liver. Amer.J. Surg. 120, $95-96$.

MARkowitz, J. (1952). The hepatic artery. Surg. Gynec. Obstet. 95, 644.

Wilkins, E. W., Burke, J. F. and HeAd, J. M. (1961). Surgical management of metastatic neoplasia in lung. J. thorac. cardiovasc. Surg. 42, 298. 